\section{Out of service}

\section{Decaying infrastructure is an urgent threat that scientists and engineers must help to address, says Colin Macilwain.}

T he trappings of our civilization, from flushing the toilet to posting flip comments on Twitter, rely on a set of critical infrastructures. Many of these - water systems, transport links, electricity grids and generating plants - are ageing severely in developed countries. And the ones that aren't ageing, such as mobile communications and the Internet, are of unknown resilience.

The sudden collapse of a bridge on Interstate 35 in Minneapolis, Minnesota, on 1 August 2007, like the cascade power failure that swept the northeastern United States four years earlier, was a portent of what could come to European and Asian nations if they allow their physical infrastructure to deteriorate.

The US power failure also showed the extent to which rich nations' infrastructure has evolved into a complex web of interdependence, which no one has sought to model properly and for which no authority has overall responsibility. Energy supply, for example, is critical to the operation of all the other infrastructures and is itself dependent on water supply and telecoms.

"The major change over the last 50 years has been the gradual, but ultimately seismic, shift" to an interconnected national infrastructure, where "failure in one part has a direct and damaging knock-on effect in others", noted a scathing report on the topic published earlier this year by the UK Council for Science and Technology (CST), the senior science-advisory body to the British government.

\section{Under pressure}

The problem will be further compounded by global warming. Even before climate change starts stressing existing infrastructure to the limit, the need to cut carbon emissions will transform utilities' priorities. "If you look at most water companies, for example, their biggest bill is electric power. We now have to rethink that," says Paul Jowitt of Heriot-Watt University in Edinburgh, the president of the London-based Institution of Civil Engineers.

Economists, civil engineers and other infrastructure buffs fear that it will take a series of massive failures, akin to the US incidents, for people to sit up and take notice. In the meantime, they hope that scientists and engineers can help to address the problem by demonstrating the hazards posed by the interdependency of networks, and by working with

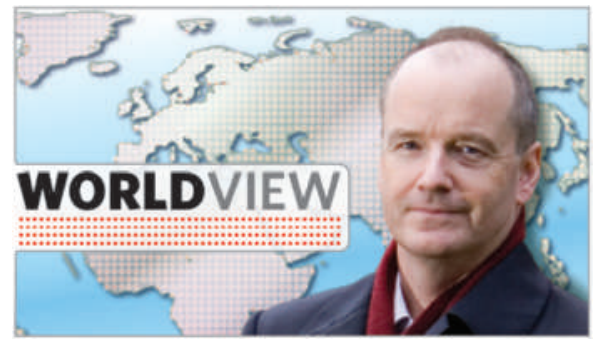

regulators and government departments on more advanced technological approaches to infrastructure repair and maintenance.

Britain is first in line to confront some aspects of this impending collapse because parts of its sewers, water system and railways date back to the early nineteenth century. The country's problems are compounded by the privatizations of the 1980s, which transferred the national infrastructure from cumbersome but technically competent state bureaucracies to profit-driven entities. None of these firms has a stake in the 50- to 75-year timescales over which infrastructure elements show their worth, and many of them have since jettisoned research and development to save money.

In Britain, according to the Organisation for Economic Co-operation and Development (OECD), investment in water, gas and electricity infrastructure fell from $0.9 \%$ of gross domestic product (GDP) in the 1970 s to $0.5 \%$ in $2000-06$. Some places, such as South Korea and Israel, have maintained higher spending levels of "What we need to
be investing in is not
consumption but
infrastructure." three or four times as much. But most, including such dirigiste nations as France, have seen infrastructure spending fall: in the OECD as a whole, it slipped from $1.7 \%$ to $0.8 \%$ of GDP over the same period.

All around the world, civil engineers, environmentalists and the business lobby are trying to push infrastructure decay on to the public agenda. And at senior government levels, awareness of the issue is growing. Australia like Britain, an early pioneer of privatization - passed legislation last year to set up a body called Infrastructure Australia to set priorities and oversee a Aus\$20-billion (US\$18.2-billion) investment fund. It swung into operation quickly, and this May published a comprehensive set of national priorities.

Also in May, an act proposing a National Infrastructure Development Bank was brought to the US Congress - but it has made no progress. President Barack Obama's stimulus package spread spending very widely, and did little to directly address a US infrastructure spending 'gap' that the American Society of Civil Engineers estimates at a cool US\$1.2 trillion over the next five years. "We've made a lot of progress at getting the problem onto the agenda, but not much progress in solving it," says Blaine Leonard, the society's president.

In Britain, Prime Minister Gordon Brown pledged in July to address one of the CST report's central recommendations by establishing a coordinating body, Infrastructure UK. Details of its remit have not been announced.

\section{Model future}

Engineers and scientists, says Leonard, should "prepare to rebuild our crumbling infrastructure with new materials and new technologies, in ways that are more resilient and more sustainable". Better models are also needed to identify critical failure paths in infrastructure, says Brian Collins, chief scientific adviser to the UK transport and business departments and a coauthor of the CST report. He says that research groups at the universities of Bristol and Warwick, and at the London School of Economics, have ideas on modelling complex systems that might prove useful.

The UK Engineering and Physical Sciences Research Council, which funds two of these groups, is now pushing national infrastructure as an ideal target for their approaches to modelling. The objective is to identify the most critical of the hundreds of linkages that exist between the different net-

works.
So where the money will come from to fix these things is anybody's guess. With some exceptions, the institution-building that has taken place has yet to make an impact in spending decisions. Private capital for infrastructure is harder to raise than ever, and most observers fear that public investment plans will collapse after the recession, as they are easier to cut than current expenditure. Dieter Helm, an economist at the University of Oxford, UK, estimated in a September report for the think tank Policy Exchange that Britain alone will need to raise about $£ 500$ billion (US $\$ 815$ billion) for infrastructure over the next ten years.

"You need a crisis first," Helm says. "What you need is for it to visibly start to fall to bits. Ultimately, people will recognize that what we need to be investing in is not consumption but infrastructure."

Colin Macilwain is based in the United Kingdom. e-mail: cfmworldview@gmail.com

See go.nature.com/ILx8PC for more columns. 